\title{
Benign migratory glossitis
}

\section{Satvinder Singh Bakshi}

Department of Ear, Nose and Throat and Head \& Neck Surgery, Mahatma Gandhi Medical College and Research Institute; Pillayarkuppam, Pondicherry, India. E-mail.: saty.bakshi@gmail.com

Received: 28th November 2016, Revised: 19th March 2017, Accepted: 20th March 2017

\section{Clinicopathological Case}

A 5-year-old girl presented with white asymptomatic lesions on the tongue for 2 months. On examination of the tongue whitish irregular patches with surrounding erythema were seen (Fig 1). The patient was diagnosed with benign migratory glossitis and the parents were reassured about her condition. Benign migratory glossitis, also known as geographic tongue, is a benign condition affecting $2-3 \%$ of the general population. It is one of the most common tongue disorders that occurs in children and has slight female preponderance. The etiology is unknown however emotional stress, allergies, diabetes and hormonal disturbances may play a role. There is increased incidence in patients with psoriasis, celiac disease and sialadenitis. The typical appearance is of an area of erythema, surrounded by a white, hyperkeratotic border. The differential diagnosis includes oral lichen planus, erythematous candidiasis, leukoplakia, and chemical burns. There is spontaneous resolution of the lesions followed by appearance of newer lesions on a different part of the tongue; other oral mucosal soft tissue sites like buccal mucosa, palate may also be affected. Most patients are asymptomatic and no treatment is required; however, some complain of increased sensitivity to hot and spicy foods in which topical anesthetics can be used for surface numbing.

Patient consent was obtained.

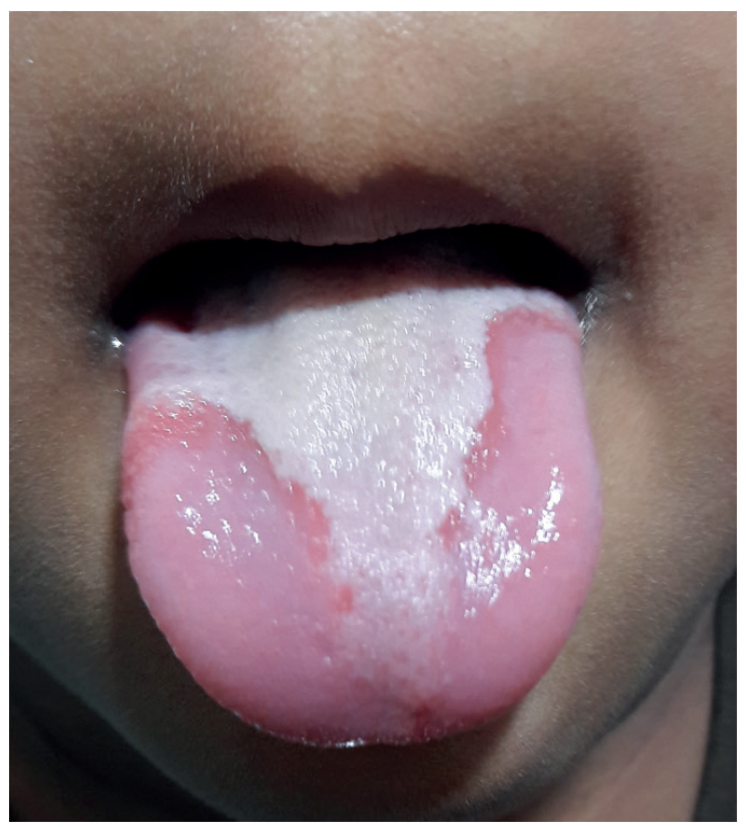

Fig. 1. Areas of bald, red smooth patches surrounded by raised white margins 